\title{
Strong convergence theorems for two total asymptotically nonexpansive nonself mappings in Banach spaces
}

\section{Hukmi Kiziltunc ${ }^{*}$ and Esra Yolacan}

\section{"Correspondence:}

hukmu@atauni.edu.tr

Department of Mathematics,

Faculty of Science, Ataturk

University, Erzurum, 25240, Turkey

\begin{abstract}
In this paper, we define and study the convergence theorems of a new two-steps iterative scheme for two total asymptotically nonexpansive nonself-mappings in Banach spaces. The results of this paper can be viewed as an improvement and extension of the corresponding results of (Shahzad in Nonlinear Anal. 61:1031-1039, 2005; Thianwan in Thai J. Math. 6:27-38, 2008; Ozdemir et al. in Discrete Dyn. Nat. Soc. 2010:307245, 2010) and all the others.
\end{abstract}

MSC: 47H09; 47H10; 46B20

Keywords: total asymptotically nonexpansive mappings; common fixed point; uniformly convex Banach space

\section{Introduction}

Let $E$ be a real normed space and $K$ be a nonempty subset of $E$. A mapping $T: K \rightarrow K$ is called nonexpansive if $\|T x-T y\| \leq\|x-y\|$ for all $x, y \in K$. A mapping $T: K \rightarrow K$ is called asymptotically nonexpansive if there exists a sequence $\left\{k_{n}\right\} \subset[1, \infty)$ with $k_{n} \rightarrow 1$ such that

$$
\left\|T^{n} x-T^{n} y\right\| \leq k_{n}\|x-y\|
$$

for all $x, y \in K$ and $n \geq 1$. Goebel and Kirk [1] proved that if $K$ is a nonempty closed and bounded subset of a uniformly convex Banach space, then every asymptotically nonexpansive self-mapping has a fixed point.

A mapping $T$ is said to be asymptotically nonexpansive in the intermediate sense (see, e.g., [2]) if it is continuous and the following inequality holds:

$$
\limsup _{n \rightarrow \infty} \sup _{x, y \in K}\left(\left\|T^{n} x-T^{n} y\right\|-\|x-y\|\right) \leq 0
$$

If $F(T):=\{x \in K: T x=x\} \neq \varnothing$ and (1.2) holds for all $x \in K, y \in F(T)$, then $T$ is called asymptotically quasi-nonexpansive in the intermediate sense. Observe that if we define

$$
a_{n}:=\sup _{x, y \in K}\left(\left\|T^{n} x-T^{n} y\right\|-\|x-y\|\right) \quad \text { and } \quad \sigma_{n}=\max \left\{0, a_{n}\right\},
$$

\section{Springer}

(c) 2013 Kiziltunc and Yolacan; licensee Springer. This is an Open Access article distributed under the terms of the Creative Commons Attribution License (http://creativecommons.org/licenses/by/2.0), which permits unrestricted use, distribution, and reproduction in any medium, provided the original work is properly cited. 
then $\sigma_{n} \rightarrow 0$ as $n \rightarrow \infty$ and (1.2) is reduced to

$$
\left\|T^{n} x-T^{n} y\right\| \leq\|x-y\|+\sigma_{n}, \quad \text { for all } x, y \in K, n \geq 1 .
$$

The class of mappings which are asymptotically nonexpansive in the intermediate sense was introduced by Bruck et al. [2]. It is known in [3] that if $K$ is a nonempty closed convex bounded subset of a uniformly convex Banach space $E$ and $T$ is a self-mapping of $K$ which is asymptotically nonexpansive in the intermediate sense, then $T$ has a fixed point. It is worth mentioning that the class of mappings which are asymptotically nonexpansive in the intermediate sense contains, properly, the class of asymptotically nonexpansive mappings.

Albert et al. [4] introduced a more general class of asymptotically nonexpansive mappings called total asymptotically nonexpansive mappings and studied methods of approximation of fixed points of mappings belonging to this class.

Definition 1 A mapping $T: K \rightarrow K$ is said to be total asymptotically nonexpansive if there exist nonnegative real sequences $\left\{\mu_{n}\right\}$ and $\left\{l_{n}\right\}, n \geq 1$ with $\mu_{n}, l_{n} \rightarrow 0$ as $n \rightarrow \infty$ and strictly increasing continuous function $\phi: \mathbb{R}^{+} \rightarrow \mathbb{R}^{+}$with $\phi(0)=0$ such that for all $x, y \in K$,

$$
\left\|T^{n} x-T^{n} y\right\| \leq\|x-y\|+\mu_{n} \phi(\|x-y\|)+l_{n}, \quad n \geq 1 .
$$

Remark 1 If $\phi(\lambda)=\lambda$, then (1.5) is reduced to

$$
\left\|T^{n} x-T^{n} y\right\| \leq\left(1+\mu_{n}\right)\|x-y\|+l_{n}, \quad n \geq 1 .
$$

In addition, if $l_{n}=0$ for all $n \geq 1$, then total asymptotically nonexpansive mappings coincide with asymptotically nonexpansive mappings. If $\mu_{n}=0$ and $l_{n}=0$ for all $n \geq 1$, we obtain from (1.5) the class of mappings that includes the class of nonexpansive mappings. If $\mu_{n}=0$ and $l_{n}=\sigma_{n}=\max \left\{0, a_{n}\right\}$, where $a_{n}:=\sup _{x, y \in K}\left(\left\|T^{n} x-T^{n} y\right\|-\|x-y\|\right)$ for all $n \geq 1$, then (1.5) is reduced to (1.4) which has been studied as mappings which are asymptotically nonexpansive in the intermediate sense.

Iterative techniques for nonexpansive and asymptotically nonexpansive mappings in Banach space including Mann type and Ishikawa type iteration processes have been studied extensively by various authors; see [1,5-11]. However, if the domain of $T, D(T)$, is a proper subset of $E$ (and this is the case in several applications) and $T$ maps $D(T)$ into $E$, then the iteration processes of Mann type and Ishikawa type have been studied by the authors mentioned above, their modifications introduced may fail to be well defined.

A subset $K$ of $E$ is said to be a retract of $E$ if there exists a continuous map $P: E \rightarrow K$ such that $P x=x$, for all $x \in K$. Every closed convex subset of a uniformly convex Banach space is a retract. A map $P: E \rightarrow K$ is said to be a retraction if $P^{2}=P$. It follows that if a map $P$ is a retraction, then $P y=y$ for all $y \in R(P)$, the range of $P$.

The concept of asymptotically nonexpansive nonself-mappings was firstly introduced by Chidume et al. [7] as the generalization of asymptotically nonexpansive self-mappings. The asymptotically nonexpansive nonself-mapping is defined as follows:

Let $K$ be a nonempty subset of real normed linear space $E$. Let $P: E \rightarrow K$ be the nonexpansive retraction of $E$ onto $K$. A nonself mapping $T: K \rightarrow E$ is called asymptotically 
nonexpansive if there exists sequence $\left\{k_{n}\right\} \subset[1, \infty), k_{n} \rightarrow 1(n \rightarrow \infty)$ such that

$$
\left\|T(P T)^{n-1} x-T(P T)^{n-1} y\right\| \leq k_{n}\|x-y\| \quad \text { for all } x, y \in K, n \geq 1 .
$$

Chidume et al. [12] introduce a more general class of total asymptotically nonexpansive mappings as the generalization of asymptotically nonexpansive nonself-mappings.

Definition 2 Let $K$ be a nonempty closed and convex subset of $E$. Let $P: E \rightarrow K$ be the nonexpansive retraction of $E$ onto $K$. A nonself map $T: K \rightarrow E$ is said to be total asymptotically nonexpansive if there exist sequences $\left\{\mu_{n}\right\}_{n \geq 1},\left\{l_{n}\right\}_{n \geq 1}$ in $[0,+\infty)$ with $\mu_{n}, l_{n} \rightarrow 0$ as $n \rightarrow \infty$ and a strictly increasing continuous function $\phi:[0,+\infty) \rightarrow[0,+\infty)$ with $\phi(0)=0$ such that for all $x, y \in K$,

$$
\left\|T(P T)^{n-1} x-T(P T)^{n-1} y\right\| \leq\|x-y\|+\mu_{n} \phi(\|x-y\|)+l_{n}, \quad n \geq 1 .
$$

Proposition 1 Let $K$ be a nonempty closed and convex subset of $E$ which is also a nonexpansive retraction of $E$ and $T_{1}, T_{2}: K \rightarrow E$ be two total nonself asymptotically nonexpansive mappings. Then there exist nonnegative real sequences $\left\{\mu_{n}\right\}_{n \geq 1},\left\{l_{n}\right\}_{n \geq 1}$ in $[0,+\infty)$ with $\mu_{n}, l_{n} \rightarrow 0$ as $n \rightarrow \infty$ and a strictly increasing continuous function $\phi: \mathbb{R}^{+} \rightarrow \mathbb{R}^{+}$with $\phi(0)=0$ such that for all $x, y \in K$,

$$
\left\|T_{i}\left(P T_{i}\right)^{n-1} x-T_{i}\left(P T_{i}\right)^{n-1} y\right\| \leq\|x-y\|+\mu_{n} \phi(\|x-y\|)+l_{n}, \quad n \geq 1,
$$

for $i=1,2$.

Proof Since $T_{i}: K \rightarrow E$ is a total nonself asymptotically nonexpansive mappings for $i=$ 1,2 , there exist nonnegative real sequences $\left\{\mu_{i n}\right\},\left\{l_{i n}\right\}, n \geq 1$ with $\mu_{i n}, l_{i n} \rightarrow 0$ as $n \rightarrow \infty$ and strictly increasing continuous function $\phi: \mathbb{R}^{+} \rightarrow \mathbb{R}^{+}$with $\phi_{i}(0)=0$ such that for all $x, y \in K$,

$$
\left\|T_{i}\left(P T_{i}\right)^{n-1} x-T_{i}\left(P T_{i}\right)^{n-1} y\right\| \leq\|x-y\|+\mu_{\text {in }} \phi_{i}(\|x-y\|)+l_{\text {in }}, \quad n \geq 1 .
$$

Setting

$$
\begin{aligned}
& \mu_{n}=\max \left\{\mu_{1 n}, \mu_{2 n}\right\}, \quad l_{n}=\max \left\{l_{1 n}, l_{2 n}\right\}, \\
& \phi(a)=\max \left\{\phi_{1}(a), \phi_{2}(a)\right\} \quad \text { for } a \geq 0,
\end{aligned}
$$

then we get nonnegative real sequences $\left\{\mu_{n}\right\},\left\{l_{n}\right\}, n \geq 1$ with $\mu_{n}, l_{n} \rightarrow 0$ as $n \rightarrow \infty$ and strictly increasing continuous function $\phi: \mathbb{R}^{+} \rightarrow \mathbb{R}^{+}$with $\phi(0)=0$ such that

$$
\begin{aligned}
\left\|T_{i}\left(P T_{i}\right)^{n-1} x-T_{i}\left(P T_{i}\right)^{n-1} y\right\| & \leq\|x-y\|+\mu_{\text {in }} \phi_{i}(\|x-y\|)+l_{\text {in }} \\
& \leq\|x-y\|+\mu_{n} \phi(\|x-y\|)+l_{n}, \quad n \geq 1,
\end{aligned}
$$

for all $x, y \in K$ and each $i=1,2$. 
In [7], Chidume et al. study the following iterative sequence:

$$
x_{n+1}=P\left(\left(1-a_{n}\right) x_{n}+a_{n} T(P T)^{n-1} x_{n}\right), \quad x_{1} \in K, n \geq 1,
$$

to approximate some fixed point of $T$ under suitable conditions. In [13], Wang generalized the iteration process (1.10) as follows:

$$
\left\{\begin{array}{l}
x_{n+1}=P\left(\left(1-\alpha_{n}\right) x_{n}+\alpha_{n} T_{1}\left(P T_{1}\right)^{n-1} y_{n}\right), \\
y_{n}=P\left(\left(1-\alpha_{n}^{\prime}\right) x_{n}+\alpha_{n}^{\prime} T_{2}\left(P T_{2}\right)^{n-1} x_{n}\right), \quad x_{1} \in K, n \geq 1,
\end{array}\right.
$$

where $T_{1}, T_{2}: K \rightarrow E$ are asymptotically nonexpansive nonself-mappings and $\left\{\alpha_{n}\right\},\left\{\alpha_{n}^{\prime}\right\}$ are sequences in $[0,1]$. They studied the strong and weak convergence of the iterative scheme (1.11) under proper conditions. Meanwhile, the results of [13] generalized the results of [7].

In [14], Shahzad studied the following iterative sequence:

$$
x_{n+1}=P\left(\left(1-a_{n}\right) x_{n}+a_{n} T P\left[\left(1-\beta_{n}\right) x_{n}+\beta_{n} T x_{n}\right]\right), \quad x_{1} \in K, n \geq 1,
$$

where $T: K \rightarrow E$ is a nonexpansive nonself-mapping and $K$ is a nonempty closed convex nonexpansive retract of a real uniformly convex Banach space $E$ with $P$ nonexpansive retraction.

Recently, Thianwan [15] generalized the iteration process (1.12) as follows:

$$
\left\{\begin{array}{l}
x_{1} \in K, \\
x_{n+1}=P\left(\left(1-\alpha_{n}-\gamma_{n}\right) x_{n}+\alpha_{n} T P\left(\left(1-\beta_{n}\right) y_{n}+\beta_{n} T y_{n}\right)+\gamma_{n} u_{n}\right), \\
y_{n}=P\left(\left(1-\alpha_{n}^{\prime}-\gamma_{n}^{\prime}\right) x_{n}+\alpha_{n}^{\prime} T P\left(\left(1-\beta_{n}^{\prime}\right) x_{n}+\beta_{n}^{\prime} T x_{n}\right)+\gamma_{n}^{\prime} v_{n}\right), \quad n \geq 1,
\end{array}\right.
$$

where $\left\{\alpha_{n}\right\},\left\{\beta_{n}\right\},\left\{\gamma_{n}\right\},\left\{\alpha_{n}^{\prime}\right\},\left\{\beta_{n}^{\prime}\right\},\left\{\gamma_{n}^{\prime}\right\}$ are appropriate sequences in $[0,1]$ and $\left\{u_{n}\right\},\left\{v_{n}\right\}$ are bounded sequences in $K$. He proved weak and strong convergence theorems for nonexpansive nonself-mappings in uniformly convex Banach spaces.

Inspired and motivated by this facts, we define and study the convergence theorems of two steps iterative sequences for total asymptotically nonexpansive nonself-mappings in Banach spaces. The results of this paper can be viewed as an improvement and extension of the corresponding results of [14-16] and others. The scheme (1.14) is defined as follows.

Let $E$ be a normed space, $K$ a nonempty convex subset of $E, P: E \rightarrow K$ the nonexpansive retraction of $E$ onto $K$ and $T_{1}, T_{2}: K \rightarrow E$ be two total asymptotically nonexpansive nonself-mappings. Then, for given $x_{1} \in K$ and $n \geq 1$, we define the sequence $\left\{x_{n}\right\}$ by the iterative scheme:

$$
\left\{\begin{array}{l}
x_{n+1}=P\left(\left(1-\alpha_{n}\right) x_{n}+\alpha_{n} T_{1}\left(P T_{1}\right)^{n-1}\left(\left(1-\beta_{n}\right) y_{n}+\beta_{n} T_{1}\left(P T_{1}\right)^{n-1} y_{n}\right)\right) \\
y_{n}=P\left(\left(1-\alpha_{n}^{\prime}\right) x_{n}+\alpha_{n}^{\prime} T_{2}\left(P T_{2}\right)^{n-1}\left(\left(1-\beta_{n}^{\prime}\right) x_{n}+\beta_{n}^{\prime} T_{2}\left(P T_{2}\right)^{n-1} x_{n}\right)\right)
\end{array}\right.
$$

where $\left\{\alpha_{n}\right\},\left\{\beta_{n}\right\},\left\{\alpha_{n}^{\prime}\right\},\left\{\beta_{n}^{\prime}\right\}$ are appropriate sequences in $[0,1]$. Clearly, the iterative scheme (1.14) is the generalization of the iterative schemes (1.11), (1.12) and (1.13).

Under suitable conditions, the sequence $\left\{x_{n}\right\}$ defined by (1.14) can also be generalized to iterative sequence with errors. Thus, all the results proved in this paper can also be 
proved for the iterative process with errors. In this case, our main iterative process (1.14) looks like

$$
\begin{aligned}
x_{1} \in K & \\
x_{n+1}= & P\left(\left(1-\alpha_{n}-\gamma_{n}\right) x_{n}+\alpha_{n} T_{1}\left(P T_{1}\right)^{n-1}\right. \\
& \left.\times\left(\left(1-\beta_{n}\right) y_{n}+\beta_{n} T_{1}\left(P T_{1}\right)^{n-1} y_{n}\right)+\gamma_{n} u_{n}\right), \\
y_{n}= & P\left(\left(1-\alpha_{n}^{\prime}-\gamma_{n}^{\prime}\right) x_{n}+\alpha_{n}^{\prime} T_{2}\left(P T_{2}\right)^{n-1}\left(\left(1-\beta_{n}^{\prime}\right) x_{n}+\beta_{n}^{\prime} T_{2}\left(P T_{2}\right)^{n-1} x_{n}\right)+\gamma_{n}^{\prime} v_{n}\right),
\end{aligned}
$$

where $\left\{\alpha_{n}\right\},\left\{\beta_{n}\right\},\left\{\gamma_{n}\right\},\left\{\alpha_{n}^{\prime}\right\},\left\{\beta_{n}^{\prime}\right\},\left\{\gamma_{n}^{\prime}\right\}$ are appropriate sequences in $[0,1]$ satisfying $\alpha_{n}+\beta_{n}+$ $\gamma_{n}=1=\alpha_{n}^{\prime}+\beta_{n}^{\prime}+\gamma_{n}^{\prime}$ and $\left\{u_{n}\right\},\left\{v_{n}\right\}$ are bounded sequences in $K$. Observe that the iterative process (1.15) with errors is reduced to the iterative process (1.14) when $\gamma_{n}=\gamma_{n}^{\prime}=0$.

The purpose of this paper is to define and study the strong convergence theorems of the new iterations for two total asymptotically nonexpansive nonself-mappings in Banach spaces.

\section{Preliminaries}

Now, we recall the well-known concepts and results.

Let $E$ be a Banach space with dimension $E \geq 2$. The modulus of $E$ is the function $\delta_{E}$ : $(0,2] \rightarrow[0,1]$ defined by

$$
\delta_{E}(\varepsilon)=\inf \left\{1-\left\|\frac{1}{2}(x+y)\right\|:\|x\|=\|y\|=1, \varepsilon=\|x-y\|\right\} .
$$

A Banach space $E$ is uniformly convex if and only if $\delta_{E}(\varepsilon)>0$ for all $\varepsilon \in(0,2]$.

The mapping $T: K \rightarrow E$ with $F(T) \neq \emptyset$ is said to satisfy condition (A) [17] if there is a nondecreasing function $f:[0, \infty) \rightarrow[0, \infty)$ with $f(0)=0, f(t)>0$ for all $t \in(0, \infty)$ such that

$$
\|x-T x\| \geq f(d(x, F(T)))
$$

for all $x \in K$, where $d(x, F(T))=\inf \{\|x-p\|: p \in F(T)\}$.

Two mappings $T_{1}, T_{2}: K \rightarrow E$ are said to satisfy condition ( $\left.\mathrm{A}^{\prime}\right)[18]$ if there is a nondecreasing function $f:[0, \infty) \rightarrow[0, \infty)$ with $f(0)=0, f(t)>0$ for all $t \in(0, \infty)$ such that

$$
\frac{1}{2}\left(\left\|x-T_{1} x\right\|+\left\|x-T_{2} x\right\|\right) \geq f(d(x, \mathcal{F}))
$$

for all $x \in K$ where $d(x, \mathcal{F})=\inf \left\{\|x-p\|: p \in \mathcal{F}=F\left(T_{1}\right) \cap F\left(T_{2}\right)\right\}$.

Note that condition ( $\mathrm{A}^{\prime}$ ) reduces to condition (A) when $T_{1}=T_{2}$ and hence is more general than the demicompactness of $T_{1}$ and $T_{2}$ [17]. A mapping $T: K \rightarrow K$ is called: (1) demicompact if any bounded sequence $\left\{x_{n}\right\}$ in $K$ such that $\left\{x_{n}-T x_{n}\right\}$ converges has a convergent subsequence; (2) semicompact (or hemicompact) if any bounded sequence $\left\{x_{n}\right\}$ in $K$ such that $\left\{x_{n}-T x_{n}\right\} \rightarrow 0$ as $n \rightarrow \infty$ has a convergent subsequence. Every demicompact mapping is semicompact but the converse is not true in general.

Senter and Dotson [17] have approximated fixed points of a nonexpansive mapping $T$ by Mann iterates, whereas Maiti and Ghosh [18] and Tan and Xu [8] have approximated the fixed points using Ishikawa iterates under the condition (A) of Senter and Dotson [17]. 
Tan and $\mathrm{Xu}$ [8] pointed out that condition (A) is weaker than the compactness of $K$. We shall use condition $\left(\mathrm{A}^{\prime}\right)$ instead of compactness of $K$ to study the strong convergence of $\left\{x_{n}\right\}$ defined in (1.14).

In the sequel, we need the following useful known lemmas to prove our main results.

Lemma $1[8]$ Let $\left\{a_{n}\right\},\left\{b_{n}\right\}$ and $\left\{c_{n}\right\}$ be sequences of nonnegative real numbers satisfying the inequality

$$
a_{n+1} \leq\left(1+b_{n}\right) a_{n}+c_{n}, \quad n \geq 1 .
$$

If $\sum_{n=1}^{\infty} c_{n}<\infty$ and $\sum_{n=1}^{\infty} b_{n}<\infty$, then

(i) $\lim _{n \rightarrow \infty} a_{n}$ exists;

(ii) In particular, if $\left\{a_{n}\right\}$ has a subsequence which converges strongly to zero, then $\lim _{n \rightarrow \infty} a_{n}=0$.

Lemma 2 [19] Let $p>1$ and $R>0$ be two fixed numbers and $E$ a Banach space. Then $E$ is uniformly convex if and only if there exists a continuous, strictly increasing and convex function $g:[0, \infty) \rightarrow[0, \infty)$ with $g(0)=0$ such that

$$
\|\lambda x+(1-\lambda) y\|^{p} \leq \lambda\|x\|^{p}+(1-\lambda)\|y\|^{p}-W_{p}(\lambda) g(\|x-y\|),
$$

for all $x, y \in B_{R}(0)=\{x \in E:\|x\| \leq R\}$ and $\lambda \in[0,1]$, where $W_{p}(\lambda)=\lambda(1-\lambda)^{p}+\lambda^{p}(1-\lambda)$.

\section{Main results}

We shall make use of the following lemmas.

Lemma 3 Let $E$ be a real Banach space, let $K$ be a nonempty closed convex subset of $E$ which is also a nonexpansive retract of $E$ and $T_{1}, T_{2}: K \rightarrow E$ be two total asymptotically nonexpansive nonself-mappings with sequences $\left\{\mu_{n}\right\},\left\{l_{n}\right\}$ defined by (1.9) such that $\sum_{n=1}^{\infty} \mu_{n}<\infty$, $\sum_{n=1}^{\infty} l_{n}<\infty$ and $\mathcal{F}:=F\left(T_{1}\right) \cap F\left(T_{2}\right)=\left\{x \in K: T_{1} x=T_{2} x=x\right\} \neq \varnothing$. Assume that there exist $M, M^{*}>0$ such that $\phi(\lambda) \leq M^{*} \lambda$ for all $\lambda \geq M, i \in\{1,2\}$. Starting from an arbitrary $x_{1} \in K$, define the sequence $\left\{x_{n}\right\}$ by recursion (1.14). Then, the sequence $\left\{x_{n}\right\}$ is bounded and $\lim _{n \rightarrow \infty}\left\|x_{n}-p\right\|$ exists, $p \in \mathcal{F}$.

Proof Let $p \in \mathcal{F}$. Set $\sigma_{n}=\left(1-\beta_{n}\right) y_{n}+\beta_{n} T_{1}\left(P T_{1}\right)^{n-1} y_{n}$ and $\delta_{n}=\left(1-\beta_{n}^{\prime}\right) x_{n}+\beta_{n}^{\prime} T_{2}\left(P T_{2}\right)^{n-1} x_{n}$.

Firstly, we note that

$$
\begin{aligned}
\left\|\delta_{n}-p\right\| & =\left\|\left(1-\beta_{n}^{\prime}\right) x_{n}+\beta_{n}^{\prime} T_{2}\left(P T_{2}\right)^{n-1} x_{n}-p\right\| \\
& \leq \beta_{n}^{\prime}\left\|T_{2}\left(P T_{2}\right)^{n-1} x_{n}-p\right\|+\left(1-\beta_{n}^{\prime}\right)\left\|x_{n}-p\right\| \\
& \leq \beta_{n}^{\prime}\left[\left\|x_{n}-p\right\|+\mu_{n} \phi\left(\left\|x_{n}-p\right\|\right)+l_{n}\right]+\left(1-\beta_{n}^{\prime}\right)\left\|x_{n}-p\right\| \\
& \leq\left\|x_{n}-p\right\|+\beta_{n}^{\prime} \mu_{n} \phi\left(\left\|x_{n}-p\right\|\right)+\beta_{n}^{\prime} l_{n} .
\end{aligned}
$$

Note that $\phi$ is an increasing function, it follows that $\phi(\lambda) \leq \phi(M)$ whenever $\lambda \leq M$ and (by hypothesis) $\phi(\lambda) \leq M^{*} \lambda$ if $\lambda \geq M$. In either case, we have

$$
\phi(\lambda) \leq \phi(M)+M^{*} \lambda
$$


for some $M>0, M^{*}>0$. Hence, from (3.1) and (3.2), we have

$$
\begin{aligned}
\left\|\delta_{n}-p\right\| & \leq\left\|x_{n}-p\right\|+\beta_{n}^{\prime} \mu_{n}\left[\phi(M)+M^{*}\left\|x_{n}-p\right\|\right]+\beta_{n}^{\prime} l_{n} \\
& \leq\left(1+M^{*} \mu_{n}\right)\left\|x_{n}-p\right\|+Q_{1}\left(\mu_{n}+l_{n}\right)
\end{aligned}
$$

for some constant $Q_{1}>0$. From (1.14) and (3.3), we have

$$
\begin{aligned}
\left\|y_{n}-p\right\|= & \left\|P\left(\left(1-\alpha_{n}^{\prime}\right) x_{n}+\alpha_{n}^{\prime} T_{2}\left(P T_{2}\right)^{n-1} \delta_{n}\right)-p\right\| \\
\leq & \left\|\left(1-\alpha_{n}^{\prime}\right) x_{n}+\alpha_{n}^{\prime} T_{2}\left(P T_{2}\right)^{n-1} \delta_{n}-p\right\| \\
\leq & \left(1-\alpha_{n}^{\prime}\right)\left\|x_{n}-p\right\|+\alpha_{n}^{\prime}\left\|T_{2}\left(P T_{2}\right)^{n-1} \delta_{n}-p\right\| \\
\leq & \alpha_{n}^{\prime}\left[\left\|\delta_{n}-p\right\|+\mu_{n} \phi\left(\left\|\delta_{n}-p\right\|\right)+l_{n}\right]+\left(1-\alpha_{n}^{\prime}\right)\left\|x_{n}-p\right\| \\
\leq & \alpha_{n}^{\prime}\left[\left(1+M^{*} \mu_{n}\right)\left\|x_{n}-p\right\|+Q_{1}\left(\mu_{n}+l_{n}\right)\right] \\
& +\alpha_{n}^{\prime} \mu_{n}\left[\phi(M)+M^{*}\left\|\delta_{n}-p\right\|\right] \\
& +\alpha_{n}^{\prime} l_{n}+\left(1-\alpha_{n}^{\prime}\right)\left\|x_{n}-p\right\| \\
\leq & \left\|x_{n}-p\right\|+M^{*} \mu_{n}\left\|x_{n}-p\right\|+M^{*} \mu_{n}\left\|\delta_{n}-p\right\| \\
& +Q_{1}\left(\mu_{n}+l_{n}\right)+\mu_{n} \phi(M)+l_{n} \\
\leq & \left\|x_{n}-p\right\|+M^{*}\left(2+M^{*} \mu_{n}\right) \mu_{n}\left\|x_{n}-p\right\| \\
& +M^{*} Q_{1} \mu_{n}\left(\mu_{n}+l_{n}\right)+Q_{1}\left(\mu_{n}+l_{n}\right)+\mu_{n} \phi(M)+l_{n} \\
\leq & \left(1+M_{2} \mu_{n}\right)\left\|x_{n}-p\right\|+Q_{2}\left(\mu_{n}+l_{n}\right)
\end{aligned}
$$

for some constant $M_{2}, Q_{2}>0$. Similarly, we have

$$
\begin{aligned}
\left\|\sigma_{n}-p\right\| & =\left\|\left(1-\beta_{n}\right) y_{n}+\beta_{n} T_{1}\left(P T_{1}\right)^{n-1} y_{n}-p\right\| \\
& \leq \beta_{n}\left\|T_{1}\left(P T_{1}\right)^{n-1} y_{n}-p\right\|+\left(1-\beta_{n}\right)\left\|y_{n}-p\right\| \\
& \leq \beta_{n}\left[\left\|y_{n}-p\right\|+\mu_{n} \phi\left(\left\|y_{n}-p\right\|\right)+l_{n}\right]+\left(1-\beta_{n}\right)\left\|y_{n}-p\right\| \\
& \leq\left\|y_{n}-p\right\|+\beta_{n} \mu_{n}\left[\phi(M)+M^{*}\left\|y_{n}-p\right\|\right]+\beta_{n} l_{n} \\
& \leq\left(1+M^{*} \mu_{n}\right)\left\|y_{n}-p\right\|+Q_{3}\left(\mu_{n}+l_{n}\right)
\end{aligned}
$$

for some constant $Q_{3}>0$. Substituting (3.4) into (3.5)

$$
\begin{aligned}
\left\|\sigma_{n}-p\right\| \leq & \left(1+M^{*} \mu_{n}\right)\left\|y_{n}-p\right\|+Q_{3}\left(\mu_{n}+l_{n}\right) \\
\leq & \left(1+M^{*} \mu_{n}\right)\left[\left(1+M_{2} \mu_{n}\right)\left\|x_{n}-p\right\|\right. \\
& \left.+Q_{2}\left(\mu_{n}+l_{n}\right)\right]+Q_{3}\left(\mu_{n}+l_{n}\right) \\
\leq & \left\|x_{n}-p\right\|+\left(M_{2}+M^{*}+M^{*} \mu_{n} M_{2}\right) \mu_{n}\left\|x_{n}-p\right\| \\
& +Q_{2}\left(\mu_{n}+l_{n}\right)+M^{*} Q_{2} \mu_{n}\left(\mu_{n}+l_{n}\right) \\
& +Q_{3}\left(\mu_{n}+l_{n}\right) \\
\leq & \left(1+M_{3} \mu_{n}\right)\left\|x_{n}-p\right\|+Q_{4}\left(\mu_{n}+l_{n}\right)
\end{aligned}
$$


for some constant $M_{3}, Q_{4}>0$. It follows from (1.14) and (3.6) that

$$
\begin{aligned}
\left\|x_{n+1}-p\right\|= & \left\|P\left(\left(1-\alpha_{n}\right) x_{n}+\alpha_{n} T_{1}\left(P T_{1}\right)^{n-1} \sigma_{n}\right)-p\right\| \\
\leq & \left\|\left(1-\alpha_{n}\right) x_{n}+\alpha_{n} T_{1}\left(P T_{1}\right)^{n-1} \sigma_{n}-p\right\| \\
\leq & \left(1-\alpha_{n}\right)\left\|x_{n}-p\right\|+\alpha_{n}\left\|T_{1}\left(P T_{1}\right)^{n-1} \sigma_{n}-p\right\| \\
\leq & \alpha_{n}\left[\left\|\sigma_{n}-p\right\|+\mu_{n} \phi\left(\left\|\sigma_{n}-p\right\|\right)+l_{n}\right] \\
& +\left(1-\alpha_{n}\right)\left\|x_{n}-p\right\| \\
\leq & \alpha_{n}\left[\left(1+M_{3} \mu_{n}\right)\left\|x_{n}-p\right\|+Q_{4}\left(\mu_{n}+l_{n}\right)\right] \\
& +\alpha_{n} \mu_{n}\left[\phi(M)+M^{*}\left\|\sigma_{n}-p\right\|\right]+\alpha_{n} l_{n} \\
& +\left(1-\alpha_{n}\right)\left\|x_{n}-p\right\| \\
\leq & \left\|x_{n}-p\right\|+M_{3} \mu_{n}\left\|x_{n}-p\right\|+Q_{4}\left(\mu_{n}+l_{n}\right) \\
& +\mu_{n} \phi(M)+M^{*} \mu_{n}\left\|\sigma_{n}-p\right\|+l_{n} \\
\leq & \left\|x_{n}-p\right\|+\left(M_{3}+M^{*}+M^{*} M_{3} \mu_{n}\right) \mu_{n}\left\|x_{n}-p\right\| \\
& +M^{*} Q_{4} \mu_{n}\left(\mu_{n}+l_{n}\right)+Q_{4}\left(\mu_{n}+l_{n}\right) \\
& +\mu_{n} \phi(M)+l_{n} \\
\leq & \left(1+M_{4} \mu_{n}\right)\left\|x_{n}-p\right\|+Q_{5}\left(\mu_{n}+l_{n}\right)
\end{aligned}
$$

for some constant $M_{4}, Q_{5}>0$. Since $\sum_{n=1}^{\infty} \mu_{n}<\infty, \sum_{n=1}^{\infty} l_{n}<\infty$, by Lemma 1 , we get $\lim _{n \rightarrow \infty}\left\|x_{n}-p\right\|$ exists. This completes the proof.

Theorem 1 Let $K$ be a nonempty convex subset of a real Banach space $E$ which is also a nonexpansive retract of $E$ and $T_{1}, T_{2}: K \rightarrow E$ be two continuous total asymptotically nonexpansive nonself-mappings with sequences $\left\{\mu_{n}\right\},\left\{l_{n}\right\}$ defined by (1.9) such that $\sum_{n=1}^{\infty} \mu_{n}<\infty, \sum_{n=1}^{\infty} l_{n}<\infty$ and $\mathcal{F}:=F\left(T_{1}\right) \cap F\left(T_{2}\right)=\left\{x \in K: T_{1} x=T_{2} x=x\right\} \neq \varnothing$. Assume that there exist $M, M^{*}>0$ such that $\phi(\lambda) \leq M^{*} \lambda$ for all $\lambda \geq M, i \in\{1,2\}$. Starting from an arbitrary $x_{1} \in K$, define the sequence $\left\{x_{n}\right\}$ by recursion (1.14). Then, the sequence $\left\{x_{n}\right\}$ converges strongly to a common fixed point of $T_{1}, T_{2}$ if and only if $\liminf _{n \rightarrow \infty} d\left(x_{n}, \mathcal{F}\right)=0$, where $d\left(x_{n}, \mathcal{F}\right)=\inf _{p \in \mathcal{F}}\left\|x_{n}-p\right\|, n \geq 1$.

Proof The necessity is obvious. Indeed, if $x_{n} \rightarrow q \in \mathcal{F}(n \rightarrow \infty)$, then

$$
d\left(x_{n}, \mathcal{F}\right)=\inf _{q \in \mathcal{F}} d\left(x_{n}-q\right) \leq\left\|x_{n}-q\right\| \rightarrow 0 \quad(n \rightarrow \infty) .
$$

Now we prove sufficiency. It follows from (3.7) that for $x^{*} \in \mathcal{F}$, we have

$$
\begin{aligned}
\left\|x_{n+1}-x^{*}\right\| & \leq\left(1+M_{4} \mu_{n}\right)\left\|x_{n}-x^{*}\right\|+Q_{5}\left(\mu_{n}+l_{n}\right) \\
& =\left\|x_{n}-x^{*}\right\|+\xi_{n},
\end{aligned}
$$


where $\xi_{n}=M_{4} \mu_{n}\left\|x_{n}-x^{*}\right\|+Q_{5}\left(\mu_{n}+l_{n}\right)$. Since $\left\{x_{n}-x^{*}\right\}$ is bounded and $\sum_{n=1}^{\infty} \mu_{n}<\infty$, $\sum_{n=1}^{\infty} l_{n}<\infty$, we have $\sum_{n=1}^{\infty} \xi_{n}<\infty$. Hence, (3.8) implies

$$
\inf _{x^{*} \in \mathcal{F}}\left\|x_{n+1}-x^{*}\right\| \leq \inf _{x^{*} \in \mathcal{F}}\left\|x_{n}-x^{*}\right\|+\xi_{n}
$$

that is

$$
d\left(x_{n+1}, \mathcal{F}\right) \leq d\left(x_{n}, \mathcal{F}\right)+\xi_{n},
$$

by Lemma 1(i), it follows from (3.9) that we get $\lim _{n \rightarrow \infty} d\left(x_{n}, \mathcal{F}\right)$ exists. Noticing $\liminf _{n \rightarrow \infty} d\left(x_{n}, \mathcal{F}\right)=0$, it follows from (3.9) and Lemma 1(ii) that we have $\lim _{n \rightarrow \infty} d\left(x_{n}\right.$, $\mathcal{F})=0$.

Now, we prove that $\left\{x_{n}\right\}$ is a Cauchy sequence in $E$. In fact, from (3.8) that for any $n \geq n_{0}$, any $m \geq n_{1}$ and any $p_{1} \in \mathcal{F}$, we have that

$$
\begin{aligned}
\left\|x_{n+m}-p_{1}\right\| & \leq\left\|x_{n+m-1}-p_{1}\right\|+\xi_{n+m-1} \\
& \leq\left\|x_{n+m-2}-p_{1}\right\|+\left(\xi_{n+m-1}+\xi_{n+m-2}\right) \\
& \leq\left\|x_{n+m-3}-p_{1}\right\|+\left(\xi_{n+m-1}+\xi_{n+m-2}+\xi_{n+m-3}\right) \\
& \vdots \\
& \leq\left\|x_{n}-p_{1}\right\|+\sum_{k=n}^{n+m-1} \xi_{k} .
\end{aligned}
$$

So by (3.10), we have that

$$
\begin{aligned}
\left\|x_{n+m}-x_{n}\right\| & \leq\left\|x_{n+m}-p_{1}\right\|+\left\|x_{n}-p_{1}\right\| \\
& \leq 2\left\|x_{n}-p_{1}\right\|+\sum_{k=n}^{\infty} \xi_{k} .
\end{aligned}
$$

By the arbitrariness of $p_{1} \in \mathcal{F}$ and from (3.11), we have

$$
\left\|x_{n+m}-x_{n}\right\| \leq 2 d\left(x_{n}, \mathcal{F}\right)+\sum_{k=n}^{\infty} \xi_{k}, \quad \forall n \geq n_{0}
$$

For any given $\varepsilon>0$, there exists a positive integer $n_{1} \geq n_{0}$, such that for any $n \geq n_{1}$, $d\left(x_{n}, \mathcal{F}\right)<\frac{\varepsilon}{4}$ and $\sum_{k=n}^{\infty} \xi_{k}<\frac{\varepsilon}{2}$, we have $\left\|x_{n+m}-x_{n}\right\|<\varepsilon$ and so for any $m \geq 1$

$$
\lim _{n \rightarrow \infty}\left\|x_{n+m}-x_{n}\right\|=0 .
$$

This show that $\left\{x_{n}\right\}$ is a Cauchy sequence in $K$. Since $K$ is a closed subset of $E$ and so it is complete. Hence, there exists a $p \in K$ such that $x_{n} \rightarrow p$ as $n \rightarrow \infty$.

Finally, we have to prove that $p \in \mathcal{F}$. By contradiction, we assume that $p$ is not in $\mathcal{F}:=$ $F\left(T_{1}\right) \cap F\left(T_{2}\right)=\left\{x \in K: T_{1} x=T_{2} x=x\right\} \neq \varnothing$. Since $\mathcal{F}$ is a closed set, $d(p, \mathcal{F})>0$. Thus for all $p \in \mathcal{F}$, we have that

$$
\left\|p-p_{1}\right\| \leq\left\|p-x_{n}\right\|+\left\|x_{n}-p_{1}\right\| .
$$


This implies that

$$
d(p, \mathcal{F}) \leq\left\|p-x_{n}\right\|+d\left(x_{n}, \mathcal{F}\right)
$$

From (3.14) and (3.15) $(n \rightarrow \infty)$, we have that $d(q, \mathcal{F}) \leq 0$. This is a contradiction. Thus $p \in \mathcal{F}:=F\left(T_{1}\right) \cap F\left(T_{2}\right)=\left\{x \in K: T_{1} x=T_{2} x=x\right\} \neq \varnothing$. This completes the proof.

On the lines similar to this theorem, we can also prove the following theorem which addresses the error terms.

Theorem 2 Let $K$ be a nonempty convex subset of a real Banach space $E$ which is also a nonexpansive retract of $E$ and $T_{1}, T_{2}: K \rightarrow E$ be two continuous total asymptotically nonexpansive nonself-mappings with sequences $\left\{\mu_{n}\right\},\left\{l_{n}\right\}$ defined by (1.9) such that $\sum_{n=1}^{\infty} \mu_{n}<\infty, \sum_{n=1}^{\infty} l_{n}<\infty$ and $\mathcal{F}:=F\left(T_{1}\right) \cap F\left(T_{2}\right)=\left\{x \in K: T_{1} x=T_{2} x=x\right\} \neq \varnothing$. Assume that there exist $M, M^{*}>0$ such that $\phi(\lambda) \leq M^{*} \lambda$ for all $\lambda \geq M, i \in\{1,2\}$. Starting from an arbitrary $x_{1} \in K$, define the sequence $\left\{x_{n}\right\}$ by recursion (1.15). Suppose that $\left\{u_{n}\right\},\left\{v_{n}\right\}$ are bounded sequences in $K$ such that $\sum_{n=1}^{\infty} \gamma_{n}<\infty, \sum_{n=1}^{\infty} \gamma_{n}^{\prime}<\infty$. Then, the sequence $\left\{x_{n}\right\}$ converges strongly to a common fixed point of $T_{1}, T_{2}$ if and only if $\liminf _{n \rightarrow \infty} d\left(x_{n}, \mathcal{F}\right)=0$, where $d\left(x_{n}, \mathcal{F}\right)=\inf _{p \in \mathcal{F}}\left\|x_{n}-p\right\|, n \geq 1$.

Lemma 4 Let $K$ be a nonempty convex subset of a uniformly convex Banach space $E$ which is also a nonexpansive retract of $E$ and $T_{1}, T_{2}: K \rightarrow E$ be two total asymptotically nonexpansive nonself-mappings with sequences $\left\{\mu_{n}\right\},\left\{l_{n}\right\}$ defined by (1.9) such that $\sum_{n=1}^{\infty} \mu_{n}<\infty$, $\sum_{n=1}^{\infty} l_{n}<\infty$ and $\mathcal{F}:=F\left(T_{1}\right) \cap F\left(T_{2}\right)=\left\{x \in K: T_{1} x=T_{2} x=x\right\} \neq \varnothing$. Assume that there exist $M, M^{*}>0$ such that $\phi(\lambda) \leq M^{*} \lambda$ for all $\lambda \geq M, i \in\{1,2\}$. Starting from an arbitrary $x_{1} \in K$, define the sequence $\left\{x_{n}\right\}$ by recursion (1.14). Suppose that

(i) $0<\liminf _{n \rightarrow \infty} \alpha_{n}$ and $0<\liminf _{n \rightarrow \infty} \beta_{n}<\limsup _{n \rightarrow \infty} \beta_{n}<1$, and

(ii) $0<\liminf _{n \rightarrow \infty} \alpha_{n}^{\prime}$ and $0<\liminf _{n \rightarrow \infty} \beta_{n}^{\prime}<\lim _{\sup } \sin _{n \rightarrow \infty} \beta_{n}^{\prime}<1$.

Then $\lim _{n \rightarrow \infty}\left\|x_{n}-T_{i}\left(P T_{i}\right)^{n-1} x_{n}\right\|=0$ for $i=1,2$.

Proof Let $p \in \mathcal{F}$. Then by Lemma $3, \lim _{n \rightarrow \infty}\left\|x_{n}-p\right\|$ exists. Let $\lim _{n \rightarrow \infty}\left\|x_{n}-p\right\|=r$. If $r=0$, then by the continuity of $T_{1}$ and $T_{2}$ the conclusion follows. Now suppose $r>0$. Set $\sigma_{n}=\left(1-\beta_{n}\right) y_{n}+\beta_{n} T_{1}\left(P T_{1}\right)^{n-1} y_{n}$ and $\delta_{n}=\left(1-\beta_{n}^{\prime}\right) x_{n}+\beta_{n}^{\prime} T_{2}\left(P T_{2}\right)^{n-1} x_{n}$. Since $\left\{x_{n}\right\}$ is bounded, there exists an $R>0$ such that $x_{n}-p, y_{n}-p \in B_{R}(0)$ for all $n \geq 1$. Using Lemma 2, we have, for some constant $A_{1}>0$, that

$$
\begin{aligned}
\left\|\delta_{n}-p\right\|^{2}= & \left\|\left(1-\beta_{n}^{\prime}\right) x_{n}+\beta_{n}^{\prime} T_{2}\left(P T_{2}\right)^{n-1} x_{n}-p\right\|^{2} \\
\leq & \left(1-\beta_{n}^{\prime}\right)\left\|x_{n}-p\right\|^{2}+\beta_{n}^{\prime}\left\|T_{2}\left(P T_{2}\right)^{n-1} x_{n}-p\right\|^{2} \\
& -\beta_{n}^{\prime}\left(1-\beta_{n}^{\prime}\right) g\left(\left\|x_{n}-T_{2}\left(P T_{2}\right)^{n-1} x_{n}\right\|\right) \\
\leq & \left(1-\beta_{n}^{\prime}\right)\left\|x_{n}-p\right\|^{2}+\beta_{n}^{\prime}\left[\left\|x_{n}-p\right\|+\mu_{n} \phi\left(\left\|x_{n}-p\right\|\right)+l_{n}\right]^{2} \\
& -\beta_{n}^{\prime}\left(1-\beta_{n}^{\prime}\right) g\left(\left\|x_{n}-T_{2}\left(P T_{2}\right)^{n-1} x_{n}\right\|\right) \\
\leq & \left\|x_{n}-p\right\|^{2}+A_{1}\left(\mu_{n}+l_{n}\right) \\
& -\beta_{n}^{\prime}\left(1-\beta_{n}^{\prime}\right) g\left(\left\|x_{n}-T_{2}\left(P T_{2}\right)^{n-1} x_{n}\right\|\right) .
\end{aligned}
$$


It follows from (1.14), Lemma 2, (3.2) and (3.16) that for some constant $A_{2}>0$,

$$
\begin{aligned}
\left\|y_{n}-p\right\|^{2}= & \left\|P\left(\left(1-\alpha_{n}^{\prime}\right) x_{n}+\alpha_{n}^{\prime} T_{2}\left(P T_{2}\right)^{n-1} \delta_{n}\right)-p\right\|^{2} \\
\leq & \left\|\left(1-\alpha_{n}^{\prime}\right)\left(x_{n}-p\right)+\alpha_{n}^{\prime}\left(T_{2}\left(P T_{2}\right)^{n-1} \delta_{n}-p\right)\right\|^{2} \\
\leq & \left(1-\alpha_{n}^{\prime}\right)\left\|x_{n}-p\right\|^{2}+\alpha_{n}^{\prime}\left\|T_{2}\left(P T_{2}\right)^{n-1} \delta_{n}-p\right\|^{2} \\
& -\alpha_{n}^{\prime}\left(1-\alpha_{n}^{\prime}\right) g\left(\left\|x_{n}-T_{2}\left(P T_{2}\right)^{n-1} \delta_{n}\right\|\right) \\
\leq & \left(1-\alpha_{n}^{\prime}\right)\left\|x_{n}-p\right\|^{2}+\alpha_{n}^{\prime}\left[\left\|\delta_{n}-p\right\|+\mu_{n} \phi\left(\left\|\delta_{n}-p\right\|\right)+l_{n}\right]^{2} \\
& -\alpha_{n}^{\prime}\left(1-\alpha_{n}^{\prime}\right) g\left(\left\|x_{n}-T_{2}\left(P T_{2}\right)^{n-1} \delta_{n}\right\|\right) \\
\leq & \left\|x_{n}-p\right\|^{2}+A_{2}\left(\mu_{n}+l_{n}\right) \\
& -\alpha_{n}^{\prime} \beta_{n}^{\prime}\left(1-\beta_{n}^{\prime}\right) g\left(\left\|x_{n}-T_{2}\left(P T_{2}\right)^{n-1} x_{n}\right\|\right) \\
& -\alpha_{n}^{\prime}\left(1-\alpha_{n}^{\prime}\right) g\left(\left\|x_{n}-T_{2}\left(P T_{2}\right)^{n-1} \delta_{n}\right\|\right) .
\end{aligned}
$$

Using Lemma 2 and (3.17), we have, for some constant $A_{3}>0$, that

$$
\begin{aligned}
\left\|\sigma_{n}-p\right\|^{2}= & \left\|\left(1-\beta_{n}\right) y_{n}+\beta_{n} T_{1}\left(P T_{1}\right)^{n-1} y_{n}-p\right\|^{2} \\
\leq & \left\|\left(1-\beta_{n}\right)\left(y_{n}-p\right)+\beta_{n}\left(T_{1}\left(P T_{1}\right)^{n-1} y_{n}-p\right)\right\|^{2} \\
\leq & \left(1-\beta_{n}\right)\left\|y_{n}-p\right\|^{2}+\beta_{n}\left\|T_{1}\left(P T_{1}\right)^{n-1} y_{n}-p\right\|^{2} \\
& -\beta_{n}\left(1-\beta_{n}\right) g\left(\left\|y_{n}-T_{1}\left(P T_{1}\right)^{n-1} y_{n}\right\|\right) \\
\leq & \left(1-\beta_{n}\right)\left\|y_{n}-p\right\|^{2}+\beta_{n}\left[\left\|y_{n}-p\right\|+\mu_{n} \phi\left(\left\|y_{n}-p\right\|\right)+l_{n}\right]^{2} \\
& -\beta_{n}\left(1-\beta_{n}\right) g\left(\left\|y_{n}-T_{1}\left(P T_{1}\right)^{n-1} y_{n}\right\|\right) \\
\leq & \left\|y_{n}-p\right\|^{2}+A_{3}\left(\mu_{n}+l_{n}\right) \\
& -\beta_{n}\left(1-\beta_{n}\right) g\left(\left\|y_{n}-T_{1}\left(P T_{1}\right)^{n-1} y_{n}\right\|\right) \\
\leq & \left\|x_{n}-p\right\|^{2}+A_{2}\left(\mu_{n}+l_{n}\right)+A_{3}\left(\mu_{n}+l_{n}\right) \\
& -\beta_{n}\left(1-\beta_{n}\right) g\left(\left\|y_{n}-T_{1}\left(P T_{1}\right)^{n-1} y_{n}\right\|\right) \\
& -\alpha_{n}^{\prime}\left(1-\alpha_{n}^{\prime}\right) g\left(\left\|x_{n}-T_{2}\left(P T_{2}\right)^{n-1} \delta_{n}\right\|\right) \\
& -\alpha_{n}^{\prime} \beta_{n}^{\prime}\left(1-\beta_{n}^{\prime}\right) g\left(\left\|x_{n}-T_{2}\left(P T_{2}\right)^{n-1} x_{n}\right\|\right) .
\end{aligned}
$$

Similarly, it follows from (1.14), Lemma 2, (3.2) and (3.18) that for some constant $A_{4}>0$,

$$
\begin{aligned}
\left\|x_{n+1}-p\right\|^{2}= & \left\|P\left(\left(1-\alpha_{n}\right) x_{n}+\alpha_{n} T_{1}\left(P T_{1}\right)^{n-1} \sigma_{n}\right)-p\right\|^{2} \\
\leq & \left\|\left(1-\alpha_{n}\right)\left(x_{n}-p\right)+\alpha_{n}\left(T_{1}\left(P T_{1}\right)^{n-1} \sigma_{n}-p\right)\right\|^{2} \\
\leq & \left(1-\alpha_{n}\right)\left\|x_{n}-p\right\|^{2}+\alpha_{n}\left\|T_{1}\left(P T_{1}\right)^{n-1} \sigma_{n}-p\right\|^{2} \\
& -\alpha_{n}\left(1-\alpha_{n}\right) g\left(\left\|x_{n}-T_{1}\left(P T_{1}\right)^{n-1} \sigma_{n}\right\|\right) \\
\leq & \left(1-\alpha_{n}\right)\left\|x_{n}-p\right\|^{2}+\alpha_{n}\left[\left\|\sigma_{n}-p\right\|+\mu_{n} \phi\left(\left\|\sigma_{n}-p\right\|\right)+l_{n}\right]^{2} \\
& -\alpha_{n}\left(1-\alpha_{n}\right) g\left(\left\|x_{n}-T_{1}\left(P T_{1}\right)^{n-1} \sigma_{n}\right\|\right) \\
\leq & \left\|x_{n}-p\right\|^{2}+A_{4}\left(\mu_{n}+l_{n}\right)
\end{aligned}
$$




$$
\begin{aligned}
& -\alpha_{n}\left(1-\alpha_{n}\right) g\left(\left\|x_{n}-T_{1}\left(P T_{1}\right)^{n-1} \sigma_{n}\right\|\right) \\
& -\alpha_{n} \beta_{n}\left(1-\beta_{n}\right) g\left(\left\|y_{n}-T_{1}\left(P T_{1}\right)^{n-1} y_{n}\right\|\right) \\
& -\alpha_{n} \alpha_{n}^{\prime}\left(1-\alpha_{n}^{\prime}\right) g\left(\left\|x_{n}-T_{2}\left(P T_{2}\right)^{n-1} \delta_{n}\right\|\right) \\
& -\alpha_{n} \alpha_{n}^{\prime} \beta_{n}^{\prime}\left(1-\beta_{n}^{\prime}\right) g\left(\left\|x_{n}-T_{2}\left(P T_{2}\right)^{n-1} x_{n}\right\|\right) .
\end{aligned}
$$

It follows from (3.19) that

$$
\begin{aligned}
\alpha_{n} \alpha_{n}^{\prime} \beta_{n}^{\prime}\left(1-\beta_{n}^{\prime}\right) g\left(\left\|x_{n}-T_{2}\left(P T_{2}\right)^{n-1} x_{n}\right\|\right) \leq & \left\|x_{n}-p\right\|^{2}-\left\|x_{n+1}-p\right\|^{2} \\
& +A_{4}\left(\mu_{n}+l_{n}\right)
\end{aligned}
$$

and

$$
\begin{aligned}
\alpha_{n} \alpha_{n}^{\prime}\left(1-\alpha_{n}^{\prime}\right) g\left(\left\|x_{n}-T_{2}\left(P T_{2}\right)^{n-1} \delta_{n}\right\|\right) \leq & \left\|x_{n}-p\right\|^{2}-\left\|x_{n+1}-p\right\|^{2} \\
& +A_{4}\left(\mu_{n}+l_{n}\right), \\
\alpha_{n} \beta_{n}\left(1-\beta_{n}\right) g\left(\left\|y_{n}-T_{1}\left(P T_{1}\right)^{n-1} y_{n}\right\|\right) \leq & \left\|x_{n}-p\right\|^{2}-\left\|x_{n+1}-p\right\|^{2} \\
& +A_{4}\left(\mu_{n}+l_{n}\right), \\
\alpha_{n}\left(1-\alpha_{n}\right) g\left(\left\|x_{n}-T_{1}\left(P T_{1}\right)^{n-1} \sigma_{n}\right\|\right) \leq & \left\|x_{n}-p\right\|^{2}-\left\|x_{n+1}-p\right\|^{2} \\
& +A_{4}\left(\mu_{n}+l_{n}\right) .
\end{aligned}
$$

Since $0<\liminf _{n \rightarrow \infty} \alpha_{n}, 0<\liminf _{n \rightarrow \infty} \alpha_{n}^{\prime}$ and $0<\liminf _{n \rightarrow \infty} \beta_{n}^{\prime}<\limsup _{n \rightarrow \infty} \beta_{n}^{\prime}<1$, there exists $n_{0} \in \mathbb{N}$ and $n_{1}, n_{2}, n_{3}, n_{4} \in(0,1)$ such that $0<n_{1}<\alpha_{n}, 0<n_{2}<\alpha_{n}^{\prime}$ and $0<n_{3}<$ $\beta_{n}^{\prime}<n_{4}<1$ for all $n \geq n_{0}$. This implies by (3.20) that

$$
\begin{aligned}
& n_{1} n_{2} n_{3}\left(1-n_{4}\right) g\left(\left\|x_{n}-T_{2}\left(P T_{2}\right)^{n-1} x_{n}\right\|\right) \leq\left\|x_{n}-p\right\|^{2}-\left\|x_{n+1}-p\right\|^{2} \\
& +A_{4}\left(\mu_{n}+l_{n}\right)
\end{aligned}
$$

for all $n \geq n_{0}$. It follows from (3.24) that $k \geq n_{0}$, we have

$$
\begin{aligned}
& \sum_{n=n_{0}}^{k} g\left(\left\|x_{n}-T_{2}\left(P T_{2}\right)^{n-1} x_{n}\right\|\right) \\
& \quad \leq \frac{1}{n_{1} n_{2} n_{3}\left(1-n_{4}\right)}\left(\sum_{n=n_{0}}^{k}\left(\left\|x_{n}-p\right\|^{2}-\left\|x_{n+1}-p\right\|^{2}\right)+A_{4} \sum_{n=n_{0}}^{k}\left(\mu_{n}+l_{n}\right)\right) \\
& \quad \leq \frac{1}{n_{1} n_{2} n_{3}\left(1-n_{4}\right)}\left(\left\|x_{n_{0}}-p\right\|^{2}+A_{4} \sum_{n=n_{0}}^{k}\left(\mu_{n}+l_{n}\right)\right) .
\end{aligned}
$$

Then $\sum_{n=n_{0}}^{\infty} g\left(\left\|x_{n}-T_{2}\left(P T_{2}\right)^{n-1} x_{n}\right\|\right)<\infty$ and therefore $\lim _{n \rightarrow \infty} g\left(\left\|x_{n}-T_{2}\left(P T_{2}\right)^{n-1} x_{n}\right\|\right)=$ 0 . Since $g$ is strictly increasing and continuous with $g(0)=0$, we have

$$
\lim _{n \rightarrow \infty}\left\|x_{n}-T_{2}\left(P T_{2}\right)^{n-1} x_{n}\right\|=0
$$


By a similar method, together with (3.21), (3.22) and (3.23), it can be show that

$$
\begin{aligned}
& \lim _{n \rightarrow \infty}\left\|x_{n}-T_{2}\left(P T_{2}\right)^{n-1} \delta_{n}\right\|=0, \quad \lim _{n \rightarrow \infty}\left\|y_{n}-T_{1}\left(P T_{1}\right)^{n-1} y_{n}\right\|=0, \\
& \lim _{n \rightarrow \infty}\left\|x_{n}-T_{1}\left(P T_{1}\right)^{n-1} \sigma_{n}\right\|=0 .
\end{aligned}
$$

It follows from (1.14) that

$$
\left\|y_{n}-x_{n}\right\|=\left\|P\left(\left(1-\alpha_{n}^{\prime}\right) x_{n}+\alpha_{n}^{\prime} T_{2}\left(P T_{2}\right)^{n-1} \delta_{n}\right)-P x_{n}\right\| \leq\left\|T_{2}\left(P T_{2}\right)^{n-1} \delta_{n}-x_{n}\right\| .
$$

This together with (3.26) implies that

$$
\lim _{n \rightarrow \infty}\left\|y_{n}-x_{n}\right\|=0 \text {. }
$$

It follows from (3.26) and (3.27) that

$$
\begin{aligned}
\left\|T_{1}\left(P T_{1}\right)^{n-1} x_{n}-x_{n}\right\| \leq & \left\|T_{1}\left(P T_{1}\right)^{n-1} x_{n}-T_{1}\left(P T_{1}\right)^{n-1} y_{n}\right\| \\
& +\left\|T_{1}\left(P T_{1}\right)^{n-1} y_{n}-y_{n}\right\|+\left\|y_{n}-x_{n}\right\| \\
\leq & \left\|y_{n}-x_{n}\right\|+\mu_{n} \phi\left(\left\|y_{n}-x_{n}\right\|\right)+l_{n} \\
& \quad+\left\|T_{1}\left(P T_{1}\right)^{n-1} y_{n}-y_{n}\right\|+\left\|y_{n}-x_{n}\right\| \\
\rightarrow & 0, \quad \text { as } n \rightarrow \infty .
\end{aligned}
$$

That is $\lim _{n \rightarrow \infty}\left\|T_{1}\left(P T_{1}\right)^{n-1} x_{n}-x_{n}\right\|=0$. The proof is completed.

Theorem 3 Let $K$ be a nonempty convex subset of a real Banach space $E$ which is also a nonexpansive retract of $E$ and $T_{1}, T_{2}: K \rightarrow E$ be two continuous total asymptotically nonexpansive nonself-mappings with sequences $\left\{\mu_{n}\right\},\left\{l_{n}\right\}$ defined by (1.9) such that $\sum_{n=1}^{\infty} \mu_{n}<\infty, \sum_{n=1}^{\infty} l_{n}<\infty$ and $\mathcal{F}:=F\left(T_{1}\right) \cap F\left(T_{2}\right)=\left\{x \in K: T_{1} x=T_{2} x=x\right\} \neq \varnothing$. Assume that there exist $M, M^{*}>0$ such that $\phi(\lambda) \leq M^{*} \lambda$ for all $\lambda \geq M, i \in\{1,2\}$; and that one of $T_{1}, T_{2}$ is demicompact (without loss of generality, we assume $T_{1}$ is demicompact). Starting from an arbitrary $x_{1} \in K$, define the sequence $\left\{x_{n}\right\}$ by recursion (1.14). Suppose that

(i) $0<\liminf _{n \rightarrow \infty} \alpha_{n}$ and $0<\liminf _{n \rightarrow \infty} \beta_{n}<\limsup _{n \rightarrow \infty} \beta_{n}<1$, and

(ii) $0<\liminf _{n \rightarrow \infty} \alpha_{n}^{\prime}$ and $0<\liminf _{n \rightarrow \infty} \beta_{n}^{\prime}<\limsup _{n \rightarrow \infty} \beta_{n}^{\prime}<1$.

Then the sequence $\left\{x_{n}\right\}$ converges strongly to some common fixed points of $T_{1}$ and $T_{2}$.

Proof It follows from (1.14) and (3.26) that

$$
\begin{aligned}
\left\|x_{n+1}-x_{n}\right\| & =\left\|P\left(\left(1-\alpha_{n}\right) x_{n}+\alpha_{n} T_{1}\left(P T_{1}\right)^{n-1} \sigma_{n}\right)-P x_{n}\right\| \leq\left\|T_{1}\left(P T_{1}\right)^{n-1} \sigma_{n}-x_{n}\right\| \\
& \rightarrow 0, \quad \text { as } n \rightarrow \infty .
\end{aligned}
$$

It follows Lemma 4 and (3.29) that

$$
\begin{aligned}
\left\|x_{n}-T_{i}\left(P T_{i}\right)^{n-2} x_{n}\right\| \leq & \left\|x_{n}-x_{n-1}\right\|+\left\|x_{n-1}-T_{i}\left(P T_{i}\right)^{n-2} x_{n-1}\right\| \\
& +\left\|T_{i}\left(P T_{i}\right)^{n-2} x_{n-1}-T_{i}\left(P T_{i}\right)^{n-2} x_{n}\right\|
\end{aligned}
$$




$$
\begin{aligned}
\leq & 2\left\|x_{n}-x_{n-1}\right\|+\left\|x_{n-1}-T_{i}\left(P T_{i}\right)^{n-2} x_{n-1}\right\| \\
& +\mu_{n-1} \phi\left(\left\|x_{n}-x_{n-1}\right\|\right)+l_{n-1} \\
\rightarrow & 0, \quad \text { as } n \rightarrow \infty, \text { for } i=1,2 .
\end{aligned}
$$

Since $T_{i}$ is continuous and $P$ is nonexpansive retraction, it follows from (3.30) that for $i=1,2$

$$
\begin{aligned}
\left\|T_{i}\left(P T_{i}\right)^{n-1} x_{n}-T_{i} x_{n}\right\| & =\left\|T_{i} P\left(T_{i}\left(P T_{i}\right)^{n-2}\right) x_{n}-T_{i} P x_{n}\right\| \\
& \rightarrow 0, \quad \text { as } n \rightarrow \infty .
\end{aligned}
$$

Hence, by Lemma 4 and (3.31), we have

$$
\begin{aligned}
\left\|x_{n}-T_{i} x_{n}\right\| & \leq\left\|x_{n}-T_{i}\left(P T_{i}\right)^{n-1} x_{n}\right\|+\left\|T_{i}\left(P T_{i}\right)^{n-1} x_{n}-T_{i} x_{n}\right\| \\
& \rightarrow 0, \quad \text { as } n \rightarrow \infty, \text { for } i=1,2 .
\end{aligned}
$$

Since $T_{1}$ is demicompact, from the fact that $\lim _{n \rightarrow \infty}\left\|x_{n}-T_{1} x_{n}\right\|=0$ and $\left\{x_{n}\right\}$ is bounded, there exists a subsequence $\left\{x_{n_{k}}\right\}$ of $\left\{x_{n}\right\}$ that converges strongly to some $q \in K$ as $k \rightarrow \infty$. Hence, it follows from (3.32) that $T_{1} x_{n_{k}} \rightarrow q, T_{2} x_{n_{k}} \rightarrow q$ as $k \rightarrow \infty$ and it follows from (3.31) and $T_{i}$ is continuous that

$$
\begin{aligned}
\left\|T_{i}\left(P T_{i}\right)^{n_{k}-1} x_{n_{k}}-T_{i} q\right\| & \leq\left\|T_{i}\left(P T_{i}\right)^{n_{k}-1} x_{n_{k}}-T_{i} x_{n_{k}}\right\|+\left\|T_{i} x_{n_{k}}-T_{i} q\right\| \\
& =\left\|T_{i} P T_{i}\left(P T_{i}\right)^{n_{k}-2} x_{n_{k}}-T_{i} P x_{n_{k}}\right\|+\left\|T_{i} x_{n_{k}}-T_{i} q\right\| \\
& \rightarrow 0, \quad \text { as } n \rightarrow \infty, \text { for } i=1,2 .
\end{aligned}
$$

Observe that

$$
\left\|q-T_{1} q\right\| \leq\left\|q-x_{n_{k}}\right\|+\left\|x_{n_{k}}-T_{1}\left(P T_{1}\right)^{n_{k}-1} x_{n_{k}}\right\|+\left\|T_{1}\left(P T_{1}\right)^{n_{k}-1} x_{n_{k}}-T_{1} q\right\| .
$$

Taking limit as $k \rightarrow \infty$ and using the fact that Lemma 4 and (3.33) we have that $T_{1} q=q$ and so $q \in F\left(T_{1}\right)$. Also we get

$$
\left\|q-T_{2} q\right\| \leq\left\|q-x_{n_{k}}\right\|+\left\|x_{n_{k}}-T_{2}\left(P T_{2}\right)^{n_{k}-1} x_{n_{k}}\right\|+\left\|T_{2}\left(P T_{2}\right)^{n_{k}-1} x_{n_{k}}-T_{2} q\right\| .
$$

Taking limit as $k \rightarrow \infty$ and using the fact that Lemma 4 and (3.33) we have that $T_{2} q=q$ and so $q \in F\left(T_{2}\right)$. Therefore, we obtain that $q \in \mathcal{F}$. It follows from (3.7), Lemma 1 and $\lim _{k \rightarrow \infty} x_{n_{k}}=q$ that $\left\{x_{n}\right\}$ converges strongly to $q \in \mathcal{F}$. This completes the proof.

Theorem 4 Let $K$ be a nonempty convex subset of a real Banach space $E$ which is also a nonexpansive retract of $E$ and $T_{1}, T_{2}: K \rightarrow E$ be two continuous total asymptotically nonexpansive nonself-mappings with sequences $\left\{\mu_{n}\right\},\left\{l_{n}\right\}$ defined by (1.9) such that $\sum_{n=1}^{\infty} \mu_{n}<\infty, \sum_{n=1}^{\infty} l_{n}<\infty$ and satisfying the condition ( $\left.\mathrm{A}^{\prime}\right)$. Assume that there exist $M, M^{*}>0$ such that $\phi(\lambda) \leq M^{*} \lambda$ for all $\lambda \geq M, i \in\{1,2\}$ and $\mathcal{F}:=F\left(T_{1}\right) \cap F\left(T_{2}\right)=\{x \in K$ : $\left.T_{1} x=T_{2} x=x\right\} \neq \varnothing$. Starting from an arbitrary $x_{1} \in K$, define the sequence $\left\{x_{n}\right\}$ by recursion (1.14). Suppose that 
(i) $0<\liminf _{n \rightarrow \infty} \alpha_{n}$ and $0<\liminf _{n \rightarrow \infty} \beta_{n}<\lim \sup _{n \rightarrow \infty} \beta_{n}<1$, and

(ii) $0<\liminf _{n \rightarrow \infty} \alpha_{n}^{\prime}$ and $0<\liminf _{n \rightarrow \infty} \beta_{n}^{\prime}<\lim \sup _{n \rightarrow \infty} \beta_{n}^{\prime}<1$.

Then the sequence $\left\{x_{n}\right\}$ converges strongly to some common fixed points of $T_{1}$ and $T_{2}$.

Proof By Lemma 3, we see that $\lim _{n \rightarrow \infty}\left\|x_{n}-p\right\|$ and so, $\lim _{n \rightarrow \infty} d\left(x_{n}, \mathcal{F}\right)$ exists for all $p \in \mathcal{F}$. Also, by (3.32), $\lim _{n \rightarrow \infty}\left\|x_{n}-T_{i} x_{n}\right\|=0$ for $i=1,2$. It follows from condition (A') that

$$
\lim _{n \rightarrow \infty} f\left(d\left(x_{n}, \mathcal{F}\right)\right) \leq \lim _{n \rightarrow \infty}\left(\frac{1}{2}\left(\left\|x-T_{1} x\right\|+\left\|x-T_{2} x\right\|\right)\right)=0 .
$$

That is,

$$
\lim _{n \rightarrow \infty} f\left(d\left(x_{n}, \mathcal{F}\right)\right)=0 .
$$

Since $f:[0, \infty) \rightarrow[0, \infty)$ is a nondecreasing function satisfying $f(0)=0, f(t)>0$ for all $t \in(0, \infty)$, therefore, we have

$$
\lim _{n \rightarrow \infty} d\left(x_{n}, \mathcal{F}\right)=0
$$

Now we can take a subsequence $\left\{x_{n_{k}}\right\}$ of $\left\{x_{n}\right\}$ and sequence $\left\{y_{k}\right\} \subset \mathcal{F}$ such that $\| x_{n_{k}}-$ $y_{k} \|<2^{-k}$ for all integers $k \geq 1$. Using the proof method of Tan and Xu [8], we have

$$
\left\|x_{n_{k+1}}-y_{k}\right\| \leq\left\|x_{n_{k}}-y_{k}\right\|<2^{-k}
$$

and hence

$$
\left\|y_{k+1}-y_{k}\right\| \leq\left\|y_{k+1}-x_{n_{k+1}}\right\|+\left\|x_{n_{k+1}}-y_{k}\right\| \leq 2^{-(k+1)}+2^{-k}<2^{-k+1} .
$$

We get that $\left\{y_{k}\right\}$ is a Cauchy sequence in $\mathcal{F}$ and so it converges. Let $y_{k} \rightarrow y$. Since $\mathcal{F}$ is closed, therefore, $y \in \mathcal{F}$ and then $x_{n_{k}} \rightarrow y$. As $\lim _{n \rightarrow \infty}\left\|x_{n}-p\right\|$ exists, $x_{n} \rightarrow y \in \mathcal{F}$. This completes the proof.

In a way similar to the above, we can also prove the results involving error terms as follows.

Theorem 5 Let $K$ be a nonempty convex subset of a real Banach space $E$ which is also a nonexpansive retract of $E$ and $T_{1}, T_{2}: K \rightarrow E$ be two continuous total asymptotically nonexpansive nonself-mappings with sequences $\left\{\mu_{n}\right\},\left\{l_{n}\right\}$ defined by (1.9) such that $\sum_{n=1}^{\infty} \mu_{n}<\infty, \sum_{n=1}^{\infty} l_{n}<\infty$ and $\mathcal{F}:=F\left(T_{1}\right) \cap F\left(T_{2}\right)=\left\{x \in K: T_{1} x=T_{2} x=x\right\} \neq \varnothing$. Assume that there exist $M, M^{*}>0$ such that $\phi(\lambda) \leq M^{*} \lambda$ for all $\lambda \geq M, i \in\{1,2\}$; and that one of $T_{1}, T_{2}$ is demicompact (without loss of generality, we assume $T_{1}$ is demicompact). Starting from an arbitrary $x_{1} \in K$, define the sequence $\left\{x_{n}\right\}$ by recursion (1.15). Suppose that $\left\{u_{n}\right\}$, $\left\{v_{n}\right\}$ are bounded sequences in $K$ such that $\sum_{n=1}^{\infty} \gamma_{n}<\infty, \sum_{n=1}^{\infty} \gamma_{n}^{\prime}<\infty$. Suppose that

(i) $0<\liminf _{n \rightarrow \infty} \alpha_{n}$ and $0<\liminf _{n \rightarrow \infty} \beta_{n}<\limsup _{n \rightarrow \infty} \beta_{n}<1$, and

(ii) $0<\liminf _{n \rightarrow \infty} \alpha_{n}^{\prime}$ and $0<\liminf _{n \rightarrow \infty} \beta_{n}^{\prime}<\lim _{\lim } \sup _{n \rightarrow \infty} \beta_{n}^{\prime}<1$.

Then the sequence $\left\{x_{n}\right\}$ converges strongly to some common fixed points of $T_{1}$ and $T_{2}$. 
Theorem 6 Let $K$ be a nonempty convex subset of a real Banach space $E$ which is also a nonexpansive retract of $E$ and $T_{1}, T_{2}: K \rightarrow E$ be two continuous total asymptotically nonexpansive nonself-mappings with sequences $\left\{\mu_{n}\right\},\left\{l_{n}\right\}$ defined by (1.9) such that $\sum_{n=1}^{\infty} \mu_{n}<\infty, \sum_{n=1}^{\infty} l_{n}<\infty$ and satisfying the condition ( $\left.\mathrm{A}^{\prime}\right)$. Assume that there exist $M, M^{*}>0$ such that $\phi(\lambda) \leq M^{*} \lambda$ for all $\lambda \geq M, i \in\{1,2\}$ and $\mathcal{F}:=F\left(T_{1}\right) \cap F\left(T_{2}\right)=\{x \in$ $\left.K: T_{1} x=T_{2} x=x\right\} \neq \varnothing$. Starting from an arbitrary $x_{1} \in K$, define the sequence $\left\{x_{n}\right\}$ by recursion (1.15). Suppose that $\left\{u_{n}\right\},\left\{v_{n}\right\}$ are bounded sequences in $K$ such that $\sum_{n=1}^{\infty} \gamma_{n}<\infty$, $\sum_{n=1}^{\infty} \gamma_{n}^{\prime}<\infty$. Suppose that

(i) $0<\liminf _{n \rightarrow \infty} \alpha_{n}$ and $0<\liminf _{n \rightarrow \infty} \beta_{n}<\lim \sup _{n \rightarrow \infty} \beta_{n}<1$, and

(ii) $0<\liminf _{n \rightarrow \infty} \alpha_{n}^{\prime}$ and $0<\liminf _{n \rightarrow \infty} \beta_{n}^{\prime}<\limsup _{n \rightarrow \infty} \beta_{n}^{\prime}<1$.

Then the sequence $\left\{x_{n}\right\}$ converges strongly to some common fixed points of $T_{1}$ and $T_{2}$.

Remark 2 If $T_{1}$ and $T_{2}$ are asymptotically nonexpansive mappings, then $l_{n}=0$ and $\phi(\lambda)=\lambda$ so that the assumption that there exist $M, M^{*}>0$ such that $\phi(\lambda) \leq M^{*} \lambda$ for all $\lambda \geq M, i \in\{1,2\}$ in the above theorems is no longer needed. Hence, the results in the above theorems also hold for asymptotically nonexpansive mappings. Thus, the results in this paper improvement and extension the corresponding results of $[14,15]$ and $[16]$ from asymptotically nonexpansive (or nonexpansive) mappings to total asymptotically nonexpansive nonself-mappings under general conditions.

Example 1 Let $E$ is the real line with the usual norm $|\cdot|, K=[0, \infty)$ and $P$ be the identity mapping. Assume that $T_{1} x=x$ and $T_{2} x=\sin x$ for $x \in K$. Let $\phi$ be a strictly increasing continuous function such that $\phi: \mathbb{R}^{+} \rightarrow \mathbb{R}^{+}$with $\phi(0)=0$. Let $\left\{\mu_{n}\right\}_{n \geq 1}$ and $\left\{l_{n}\right\}_{n \geq 1}$ be two nonnegative real sequences defined by $\mu_{n}=\frac{1}{n^{2}}$ and $l_{n}=\frac{1}{n^{3}}$, for all $n \geq 1\left(\lim _{n \rightarrow \infty} \mu_{n}=0\right.$ and $\left.\lim _{n \rightarrow \infty} l_{n}=0\right)$. Since $T_{1} x=x$ for $x \in K$, we have

$$
\left|T_{1}^{n} x-T_{1}^{n} y\right| \leq|x-y|
$$

For all $x, y \in K$, we obtain

$$
\begin{aligned}
& \left|T_{1}^{n} x-T_{1}^{n} y\right|-|x-y|-\mu_{n} \phi(|x-y|)-l_{n} \\
& \quad \leq|x-y|-|x-y|-\mu_{n} \phi(|x-y|)-l_{n} \\
& \quad \leq 0
\end{aligned}
$$

for all $n=1,2, \ldots,\left\{\mu_{n}\right\}_{n \geq 1}$ and $\left\{l_{n}\right\}_{n \geq 1}$ with $\mu_{n}, l_{n} \rightarrow 0$ as $n \rightarrow \infty$ and so $T_{1}$ is a total asymptotically nonexpansive mapping. Also, $T_{2} x=\sin x$ for $x \in K$, we have

$$
\left|T_{1}^{n} x-T_{1}^{n} y\right| \leq|x-y|
$$

For all $x, y \in K$, we obtain

$$
\begin{aligned}
& \left|T_{2}^{n} x-T_{2}^{n} y\right|-|x-y|-\mu_{n} \phi(|x-y|)-l_{n} \\
& \quad \leq|x-y|-|x-y|-\mu_{n} \phi(|x-y|)-l_{n} \\
& \quad \leq 0
\end{aligned}
$$


for all $n=1,2, \ldots,\left\{\mu_{n}\right\}_{n \geq 1}$ and $\left\{l_{n}\right\}_{n \geq 1}$ with $\mu_{n}, l_{n} \rightarrow 0$ as $n \rightarrow \infty$ and so $T_{2}$ is a total asymptotically nonexpansive mapping. Clearly, $\mathcal{F}:=F\left(T_{1}\right) \cap F\left(T_{2}\right)=\{0\}$. Set

$$
\begin{aligned}
& \alpha_{n}^{\prime}=\alpha_{n}=\frac{n}{n+1}, \quad \gamma_{n}^{\prime}=\gamma_{n}=\frac{1}{n^{2}}, \\
& \beta_{n}^{\prime}=\beta_{n}=\left\{\begin{array}{ll}
\frac{1}{2}, & n \text { is even, } \\
\frac{1}{3}, & n \text { is odd }
\end{array} \text { and } \quad v_{n}=u_{n}=\frac{1}{n+1}\right.
\end{aligned}
$$

for $n \geq 1$. Thus, the conditions of Theorem 2 are fulfilled. Therefore, we can invoke Theorem 2 to demonstrate that the iterative sequence $\left\{x_{n}\right\}$ defined by (1.15) converges strongly to 0 .

\section{Competing interests}

The authors declare that they have no competing interests.

\section{Authors' contributions}

All authors contributed equally and significantly in writing this paper. All authors read and approved the final manuscript.

\section{Acknowledgements}

Dedicated to Professor Hari M Srivastava.

The authors are very grateful to the referees for their careful reading of manuscript, valuable comments and suggestions.

\section{Received: 1 December 2012 Accepted: 25 March 2013 Published: 10 April 2013}

\section{References}

1. Goebel, K, Kirk, WA: A fixed point theorem for asymptotically nonexpansive mappings. Proc. Am. Math. Soc. 35 , 171-174 (1972)

2. Bruck, RE, Kuczumow, T, Reich, S: Convergence of iterates of asymptotically nonexpansive mappings in Banach spaces with the uniform Opial property. Colloq. Math. 65, 169-179 (1993)

3. Kirk, WA: Fixed point theorems for non-Lipschitzian mappings of asymptotically nonexpansive type. Isr. J. Math. 17, 339-346 (1974)

4. Albert, $\mathrm{Yl}$, Chidume, $\mathrm{CE}$, Zegeye, $\mathrm{H}$ : Approximating fixed points of total asymptotically nonexpansive mappings. Fixed Point Theory Appl. 2006, Article ID 10673 (2006)

5. Schu, J: Weak and strong convergence of a fixed points of asymptotically nonexpansive mappings. Bull. Aust. Math. Soc. 43, 153-159 (1991)

6. Osilike, MO, Aniagbosar, SC: Weak and strong convergence theorems for fixed points of asymptotically nonexpansive mappings. Math. Comput. Model. 32, 1181-1191 (2000)

7. Chidume, CE, Ofoedu, EU, Zegeye, H: Strong and weak convergence theorems for fixed points of asymptotically nonexpansive mappings. J. Math. Anal. Appl. 280, 364-374 (2003)

8. Tan, KK, Xu, HK: Approximating fixed points of nonexpansive mappings by the Ishikawa iteration process. J. Math. Anal. Appl. 178, 301-308 (1993)

9. Khan, SH, Takahashi, W: Approximanting common fixed points of two asymptotically nonexpansive mappings. Sci. Math. Jpn. 53(1), 143-148 (2001)

10. Khan, SH, Hussain, $\mathrm{N}$ : Convergence theorems for nonself asymptotically nonexpansive mappings. Comput. Math. Appl. 55, 2544-2553 (2008)

11. Qin, $X$, Su, Y, Shang, M: Approximating common fixed points of non-self asymptotically nonexpansive mappings in Banach spaces. J. Appl. Math. Comput. 26, 233-246 (2008)

12. Chidume, CE, Ofoedu, EU: Approximation of common fixed points for finite families of total asymptotically nonexpansive mappings. J. Math. Anal. Appl. 333, 128-141 (2007)

13. Wang, L: Strong and weak convergence theorems for common fixed points of nonself asymptotically nonexpansive mappings. J. Math. Anal. Appl. 323, 550-557 (2006)

14. Shahzad, N: Approximanting fixed points of non-self nonexpansive mappings in Banach spaces. Nonlinear Anal. 61, 1031-1039 (2005)

15. Thianwan, S: Weak and strong convergence theorems for new iterations with errors for nonexpansive nonself-mapping. Thai J. Math. 6, 27-38 (2008). Special Issue (Annual Meeting in Mathematics, 2008)

16. Ozdemir, M, Akbulut, S, Kiziltunc, H: Convergence theorems on a new iteration process for two asymptotically nonexpansive nonself-mappings with errors in Banach spaces. Discrete Dyn. Nat. Soc. 2010, Article ID 307245 (2010). doi:10.1155/2010/307-245

17. Senter, HF, Dotson, WG: Approximating fixed points of nonexpansive mappings. Proc. Am. Math. Soc. 44, 375-380 (1974)

18. Maiti, N, Ghosh, MK: Approximating fixed points by Ishikawa iterates. Bull. Aust. Math. Soc. 40, 113-117 (1989)

19. Xu, HK: Inequalities in Banach spaces with applications. Nonlinear Anal. 16, 1127-1138 (1991) 
doi:10.1186/1687-1812-2013-90

Cite this article as: Kiziltunc and Yolacan: Strong convergence theorems for two total asymptotically nonexpansive nonself mappings in Banach spaces. Fixed Point Theory and Applications 2013 2013:90.

Submit your manuscript to a SpringerOpen ${ }^{\circ}$ journal and benefit from:

- Convenient online submission

- Rigorous peer review

- Immediate publication on acceptance

Open access: articles freely available online

- High visibility within the field

- Retaining the copyright to your article

Submit your next manuscript at $\gg$ springeropen.com 